\title{
DESENVOLVIMENTO LOCAL: A COMUNIDADE COMO COPARTICIPANTE
}

\section{LOCAL DEVELOPMENT: THE COMMUNITY AS CO-PARTICIPANT}

\author{
Adenilda Couto B. Pinto ${ }^{1}$
}

\section{RESUMO}

Este artigo descreve o desenvolvimento local, mas, antes, foi preciso fazer uma exposição sobre desenvolvimento, numa concepção mais ampla, a partir da Segunda Guerra Mundial, assim como uma reflexão sobre o Desenvolvimento de Comunidade (DC), desenvolvimento local e participação da comunidade. O objetivo deste artigo é compreender se a comunidade, enquanto participante, contribui para o desenvolvimento local. A pesquisa utilizada foi a bibliográfica visando compreender como se processa a discussão sobre desenvolvimento local na concepção de autores que tratam o tema. A partir desta pesquisa, nota-se que são vários os determinantes que contribuem para o desenvolvimento local e a participação da comunidade é o principal. A tomada de consciência da comunidade quanto a sua infraestrutura, suas dificuldades, sua educação, qualidade de vida, cultura, valores, desafios, dentre outros, desperta para se tornar protagonista no seu processo de mudanças e transformação social através de articulações com as escalas local, regional, estadual e nacional.

Palavras-chave: Desenvolvimento Local. DC. Participação. Cooperação. Capital social.

\begin{abstract}
This article describes about local development, but rather had to do a presentation on development, a broader conception, from the Second World War. As a reflection on the Development of Community-DC, local development and community participation. The objective of this paper is to understand if the community as a participating, contributing to local development. The survey used was the literature seeking to understand how it handles the discussion on local development in the design of writers on the subject. From this research, we note that there are several determinants that contribute to local development, and community participation is the key. The awareness of the community and its infrastructure, their difficulties, their education, quality of life, culture, values, challenges, among others, the protagonist awakens to become in the process of change and social transformation through joints with scales local, regional, state and national.
\end{abstract}

Keywords: Local Development. DC. Participation. Cooperation. Social capital.

\section{Introdução}

Há muito, o tema desenvolvimento local tem sido objeto de um número crescente de estudos. Contudo, a partir dos anos 1990 passou a ter maior atenção dos pesquisadores em decorrência da globalização.

\footnotetext{
${ }^{1}$ Universidade Católica de Salvador (UCSAL). Mestranda do curso Planejamento Territorial e Desenvolvimento Social-UCSAL. Avenida Cardeal da Silva, 205, Federação, Salvador, BA - CEP: 40231-902. E-mail: nildacouto60@ yahoo.com.br
} 
Faz-se importante e necessário estabelecer alguns pontos sobre o significado de desenvolvimento, trazendo ao debate seu processo histórico articulado ao contexto atual.

O trabalho em tela propõe analisar alguns aspectos do desenvolvimento, sobretudo acerca do desenvolvimento local a partir da Segunda Guerra Mundial. E, para isso, a pesquisa foi fundamentada nos estudos desenvolvidos pelos autores: Sachs (2004), Vieira (1981), Veiga (2005), Buarque (1999), Iamamoto (2011), Santos (1999), Singer (1999), Leroy (2002), Putnam (2004) e Sennett (2012).

Serão tomados como eixos balizadores para o desenvolvimento local os determinantes: PIB, DC, capital social e cooperação.

\section{Desenvolvimento}

Trazer à discussão o significado de desenvolvimento local requer uma maior aproximação do entendimento de desenvolvimento em seu sentido lato compreendido como estratégia do Estado, enquanto regulador, que intervém nas esferas política e social visando ao progresso e bem-estar social.

Após a Segunda Guerra Mundial, a Organização das Nações Unidas (ONU) passou a difundir o Desenvolvimento de Comunidade (DC). A ONU aliou-se aos Estados Unidos para combater o avanço do socialismo, ambos acreditavam que as comunidades pobres eram mais suscetíveis às propagandas comunistas que as sociedades ricas.

Os Estados Unidos iniciaram assistência aos países pobres, principalmente à América Latina, através de um conjunto de serviços técnicos propiciando às populações uma educação de base, um mínimo de bem-estar e de dignidade humana.

Para Sachs (2004, p. 30), "o desenvolvimento, tal como se conhece hoje, começou nos anos 1940, no contexto da preparação dos anteprojetos para a reconstrução da periferia devastada da Europa no pós-guerra”.

Na década de 1940 a ONU iniciou seus trabalhos dando assistência aos países subdesenvolvidos através de técnicas de DC.

Destarte Vieira (1981, p. 175), o 
Desenvolvimento de Comunidade se preocupa com a educação dos povos para que se tornem o agente de seu próprio progresso; não é, portanto, melhoria das condições de vida por uma ação direta externa que se almeja; não somos de opinião que melhores condições fazem melhores cidadãos; o que desejamos são melhores cidadãos promovendo melhores condições.

O DC é um processo pedagógico, técnico-metodológico, de ação junto às comunidades e tem a participação social como elemento central. É considerado também um processo de cooperação social, em que a população tem interesses e necessidades comuns, visto que ocupa o mesmo espaço.

No Brasil, o DC começou a partir de 1950 na perspectiva de criar condições de progresso econômico e social para toda a comunidade, com participação ativa desta. Tinha uma abordagem assistencialista, visava, a principio, o desenvolvimento rural através da modernização da agricultura. Iniciou no meio rural, sendo estendido, posteriormente para a área urbana. A proposta oculta do DC para os países subdesenvolvidos era de caminhar em direção aos países industrializados, contribuindo, assim, para o desenvolvimento do capitalismo.

O desenvolvimento na América Latina na década de 1950 vincula-se à percepção do homem como recurso econômico trabalhado em função do desenvolvimento econômico, e corresponde à perspectiva desenvolvimentista. Juscelino Kubitschek, presidente da época, assume a proposta do desenvolvimentismo e define sua política de modo a dar condições de operacionalidade, tais como: acesso à penetração do capital monopolista e a ideologia desenvolvimentista.

O entendimento de desenvolvimento, por muito tempo, foi sinônimo apenas de crescimento econômico, que se expressa através do Produto Interno Bruto (PIB) e da renda per capita, ligado à industrialização e ao avanço tecnológico. Hoje, desenvolvimento passou a incorporar outros aspectos, como sociais, condições de saúde, educação, habitação, dentre outros.

Para Sachs (2004, p. 14),

o crescimento, mesmo que acelerado, não é sinônimo de desenvolvimento se ele não amplia o emprego, se não reduz a pobreza e se não atenua as desigualdades, conforme enfatizado, desde os anos 1960, por M. Kalecki e Dudley Seers. 
Diante do exposto, pergunta-se: o desenvolvimento local ocorre a partir da ação de políticas externas, de cima para baixo?

Promover o desenvolvimento local não é apenas visar o crescimento econômico, mas emancipar as pessoas, garantindo o acesso aos recursos e à cidadania. Ele busca inserir no discurso do desenvolvimento a comunidade, de modo que se envolvam e gerenciem seus recursos nas escalas local, regional e nacional, tornando-a sujeito de seu processo de construção histórica.

A participação reflete o pensar e o agir do homem sobre a realidade em que vive e que está situado. É um exercício contínuo das camadas populares, um processo social que desperta o indivíduo para o enfrentamento das expressões da questão social, tornando-o sujeito social da própria história. O processo de participação da comunidade traduz-se em melhorias para o desenvolvimento local. A comunidade torna-se sujeito e agente do seu processo de desenvolvimento, através da participação, visando conquistas e melhorias.

O desenvolvimento local não é isolado, cada um por si, é fundamental a ideia de parceria, de trabalho em equipe, de objetivos comuns de coletividade, esforço articulação, formação de alianças, acordos e convênios, vantagens competitivas de cada agente, cooperação, operação conjunto, é imprescindível ao desenvolvimento do território. (VEIGA, 2005, p. 52)

Nota-se que a sustentação do desenvolvimento local decorre da compromisso e envolvimento dos atores sociais que desenvolvem iniciativas próprias a partir de suas particularidades territoriais nos planos culturais, sociais, econômicos e políticos.

O desenvolvimento local envolve estratégias e políticas influenciadas pelos protagonistas locais. Além disso, objetiva, por meios endógenos, uma integração no desenvolvimento econômico em escala macroespacial.

Para Buarque (1999, p. 9), o desenvolvimento local "é um processo endógeno registrado em pequenas unidades territoriais e agrupamentos humanos capaz de promover o dinamismo econômico e a melhoria da qualidade de vida da população”.

Nem sempre as políticas públicas e ações voltadas para as comunidades de dão com o intuito de desenvolvimento e crescimento local. No final de 1940, nas favelas do Rio de Janeiro, Distrito Federal na época, ainda na perspectiva de combater o avanço do comunismo, algumas ações foram efetivadas através da Fundação Leão XIII, primeira 
grande instituição assistencial, oficializada por Decreto-Lei da presidência da República, junto com a Prefeitura do Rio de Janeiro e Ação Social Arquidiocesana, que passou a trabalhar pela recuperação das favelas através de assistência material e moral.

Iamamoto (2011, p. 300) diz:

A constatação de que as grandes favelas dos morros cariocas (assim como das baixadas da periferia e subúrbios) poderiam transforma-se em redutos eleitorais do Partido Comunista do Brasil leva à mobilização, pelo Estado e hierarquia, de seu aparato assistencial para contrapor-se e consolidar seu controle sobre aquela população.

A atuação na favela se deu mediante implantação de serviços de transporte, alimentação, infraestrutura de esporte e lazer, merenda escolar, educação popular, dentre outros, todos integrados num projeto tutelar, na perspectiva de cooptação, controle de massas visando à legitimação do poder, do Estado.

Boaventura Santos, sociólogo, português, se preocupava em alinhar a ciência ao senso comum, por acreditar que ampliava seu conhecimento. Na década de 1970, em um dos seus estudos, resolveu viver, durante o período de sua pesquisa, em uma das favelas do Rio de Janeiro a fim de conhecer de perto aquela realidade. Durante sua vivência na favela, foi possível manter diversos contatos com líderes comunitários, com a população, com representantes de entidades, assim como com profissionais do Serviço Social vinculados à Fundação Leão XIII.

Esse pesquisador e professor ficou indignado com a intervenção profissional de alguns assistentes sociais, representantes da fundação, que tinham um discurso ideológico excludente, negando à população a construção de uma cidadania, democracia política e social. Santos (1999, p. 296) enfatiza que: 
A democracia deve ser expandida do espaço-tempo da cidadania onde aliás vigora com fortes limitações, como vimos - aos restantes espaços-tempo estruturais. Isto significa que a democracia não é uma especificidade normativa da instituição do Estado nacional. Pelo contrário, a democracia é, por assim dizer, específica de todos os espaços estruturais e de todos os níveis de sociabilidade. A especificidade reside no modo variado como ela é institucionalizada. Em cada um dos espaços-tempo, o paradigma emergente está vinculado à transformação das relações sociais, de relações de poder em relações de partilha da autoridade [...].

Em caráter oposto ao da democratização de informações e garantia de direitos, algumas ações são implementadas para a comunidade, como medidas compensatórias, a fim de desarticulá-la. Como diz Iamamoto (2011, p. 304):

O empreendimento de educação e lazeres para as classes populares se volta justamente para a ocupação desse tempo resgatado ao capital. Para ocupá-lo de uma forma que neutralize, que esterilize se conteúdo de autonomia e relativa liberdade.

A regulação estatal nas favelas foi sendo percebida já no final de 1970, o que suscitou a criação de movimentos de favela, assim como de movimentos sociais em todo o país na articulação com outras entidades buscando maior participação, autonomia e emancipação da população.

Em 1995, no Brasil, surgiu um programa que objetivava combater a pobreza através de ações em parceria com a comunidade, incentivando o desenvolvimento local integrado e sustentável das regiões mais pobres. Foi o Programa Comunidade Solidária, criado no governo de Fernando Henrique Cardoso, como um instrumento para promover a participação cidadã e novas formas de diálogo entre o Estado e a sociedade civil contra a pobreza, sendo substituído pelo Programa Fome Zero em 2002.

Com o surgimento do Programa Comunidade solidária foram extintos o Conselho Nacional de Segurança Alimentar (CONSEA) e a Legião Brasileira de Assistência (LBA), que havia sido criada em 1942 e tinha uma proposta bem assistencialista. Já o Programa Comunidade Solidária tinha uma proposta que se distanciava do clientelismo, mas visava contemplar a população a partir de seus direitos básicos.

Tinha como estratégia a parceria e a corresponsabilidade entre os mais diversos atores sociais a fim de obter êxito no combate à pobreza. Para isso, contava com uma ação conjunta dos governos federal, estaduais, municipais, organizações não 
governamentais, igrejas e a participação da população para a efetivação das ações. O programa contemplou cinco áreas: saúde, alimentação e nutrição, serviços urbanos, desenvolvimento rural, emprego, renda e, por fim, a defesa de direitos.

O discurso do programa Comunidade Solidária escondia, obscurecia os processos de dominação, uma vez que transferia a responsabilidade do Estado, que se tornava um parceiro financiador, para a sociedade civil, que era movida por causas comuns e passou a se envolver no programa.

Singer (1999), professor e economista, criticou o Programa Comunidade Solidária quando mencionou que o fato de o Conselho ter sido formado por pessoas escolhidas pelo governo, sem a participação da sociedade civil, implicou seu enfraquecimento. Assim como a falta de representatividade das ONGs enfraqueceu, também, as relações entre estas e o governo.

Ratificando a observação de Singer, o Programa Comunidade Solidária colide frontalmente com os princípios da Constituição Federal de 1988, quando não envolve a participação popular. Foi colocado como princípios pela CF brasileira de 1988 a participação da sociedade civil na gestão de políticas públicas e programas promovidos pelo governo, através dos conselhos e das conferências, espaços democráticos de discussões e debates a fim de garantir o exercício da cidadania e controle social, bem como, também, a descentralização como estratégia de efetivação da participação. Traz as políticas sociais para mais próximo da população, contribuindo para diminuir a distância entre o poder público e as decisões que fazem parte da vida cotidiana dos brasileiros.

Diante do exposto e, como já foi dito anteriormente, o desenvolvimento não se dá apenas através das políticas públicas e de programas implementados pelo governo, mas a partir do envolvimento de todos os segmentos sociais, permitindo um diálogo entre as escalas local, regional e nacional.

Como diz Buarque (1999), o desenvolvimento local implica articulação entre diversos atores e esferas de poder, seja a sociedade civil, seja as organizações não governamentais, as instituições privadas e políticas e o próprio governo. Cada um dos atores tem seu papel para contribuir com o desenvolvimento local. 
A participação do indivíduo na vida política e social é de suma importância para o desenvolvimento local quando, no exercício de sua cidadania, é cobrado que as propostas e políticas públicas sejam efetivadas no sentido de assegurar à comunidade melhores condições de vida.

Para Leroy (2002) a participação popular direta e a democracia também constituem base para o planejamento sustentável. Seu pleno exercício remete a uma sociedade participativa e consciente de seu papel no desenvolvimento do planejamento, alcançando, assim, o sustentável.

Transformar as camadas populares em sujeitos políticos de seu ambiente material, econômico e cultural - esse é o desafio da construção da sustentabilidade democrática em nosso país. A verdadeira democracia passa pela economia, mas desemboca necessariamente na justiça. É por isso que esse desafio implica estabelecer a primazia dos direitos, base e garantia da cidadania, e ampliá-los para além dos direitos civis - até o campo dos direitos econômicos, sociais, culturais e ambientais. (LEROY, 2002)

Os autores Putnam (2006) e Sennett (2012) concordam que a união de esforços, a partir da cooperação, possibilita realizar de modo mais efetivo o bem-estar da coletividade.

Sennett (2012) define a cooperação habilidosa como um ofício que tem o seu fundamento no aprendizado de escutar o outro com atenção e na capacidade de dialogar, em oposição ao debater ou discutir. Caracteriza a cooperação como o lubrificante da máquina de concretização das coisas, como partilha que permite compensar as carências individuais. Ele entende que a prática da cooperação se torna fundamental para a prosperidade da sociedade.

Os indivíduos devem tornar-se atores em busca do bem-estar social, que no entendimento de Putnam (2006) é compreendido como capital social.

Não são muitos os conceitos de capital social e há algumas controvérsias. Para Putnam (2006) diz respeito a características da organização social, tais como confiança e normas, que contribuam para elevar a eficiência da sociedade.

Os estoques de capital social, como confiança, normas e sistemas de participação, tendem a ser cumulativos e a reforçar-se mutuamente. Os círculos virtuosos redundam em equilíbrios sociais com elevados níveis de cooperação, confiança, reciprocidade, civismo e bem-estar coletivo. (PUTNAM, 2006, p. 187) 
Alguns autores acreditam que o capital social oportuniza aos membros da sociedade acesso aos recursos de capital úteis disponíveis nas relações sociais que atendem aos seus interesses em decorrência de relações baseadas em lealdade e confiança.

Putnam (2006, p. 177) afirma que “o capital social facilita a cooperação espontânea. Um bom exemplo desse princípio é a instituição de poupança informal, largamente difundida nos quatro continentes, chamada associação de crédito rotativo".

Há várias associações de crédito rotativo no mundo, o funcionamento se dá através de pessoas que resolvem contribuir regularmente para um fundo, durante um período, até que todos tenham recebido. O recebimento pelos participantes ocorrerá todo mês, por um membro diferente, que poderá gastar como quiser. No Brasil, algo similar à associação de crédito, com as mesmas normas, é utilizado, principalmente, pela classe menos favorecida, denominado "caixa".

As associações de crédito rotativo variam bastante em tamanho, composição social, organização e critérios para determinar as contribuições. Todas elas combinam sociabilidade com formação de capital em pequena escala. (PUTNAM, 2006, p. 177)

Segundo entendimento a partir de leituras de Putnam (2006), compreende-se que capital social contribui para o desenvolvimento local à medida que há um estreitamento entre as relações sociais, cooperação, interação entre indivíduos e infraestrutura visando ao bem-estar local.

Destarte Putnam (2006), quanto mais capital social, mais desenvolvimento uma sociedade teria. O capital social contribui para o desenvolvimento local?

Vários capitais impactam no determinante desenvolvimento, principalmente o capital social. O nível de confiança, de participação, os valores, as normas, tudo o que permite a cooperação entre os indivíduos está ligado ao capital social que está condicionado por aspectos políticos, sociais e culturais.

\section{Considerações finais}

Quando se começou a falar sobre o conceito de desenvolvimento, ele era muito vinculado apenas a uma lógica econômica e desenvolvimentista. Posteriormente, o 
discurso do desenvolvimento foi ampliando as concepções para lógicas sociais e políticas.

A grande importância que a discussão acerca do desenvolvimento local alcançou justifica o fato de que, sem a participação da comunidade, é muito difícil tal processo ocorrer. Já que para isso é preciso haver o desenvolvimento e a participação dos indivíduos, de modo que potencializem suas habilidades, conhecimentos a fim de gerir melhor os recursos disponíveis na comunidade para o bem-estar dos mesmos.

O Estado não é o único responsável pelas políticas de desenvolvimento, pois a comunidade também está sendo responsabilizada, coparticipante através de eixos de capital social, construção de parcerias pública, privada e comunitária.

A partir da construção deste artigo foi constatado que o desenvolvimento local não está relacionado apenas ao crescimento econômico, mas a outros determinantes, tais como: envolvimento da comunidade nos processos decisórios, articulação entre diversos atores e esferas de poder, dentre outros.

Portanto, o papel dos indivíduos na concretização das ações, tornando-se protagonista local a partir da cooperação, na resolução das demandas, é de fundamental importância para o processo de desenvolvimento local e para a melhoria da sua qualidade de vida.

\section{REFERÊNCIAS}

BUARQUE, S. C. Metodologia de planejamento do desenvolvimento local e municipal sustentável. Material para orientação técnica e treinamento de multiplicadores e técnicos em planejamento local e municipal. Brasília, DF: IICA, 1999.

IAMAMOTO, M. V.; CARVALHO, R. Relações sociais e serviço social no Brasil: esboço de uma interpretação histórico-metodológica. 34. ed. São Paulo: Cortez, 2011.

MAGALHÃES, A. F. O direito das favelas. Rio de Janeiro: Letra Capital, 2013.

PADUA, J. A.; ACSELRAD, H.; LEROY, J.-P.; BERTUCCI, A. A.; SCHLESINGER, S.; PACHECO, T. Tudo ao mesmo tempo agora. Desenvolvimento, sustentabilidade, democracia: o que isso tem a ver com você. Petrópolis: Vozes, 2002. 
PUTNAM, R. D. Comunidade e democracia: a experiência da Itália moderna. 5. ed. Rio de Janeiro: Fundação Getúlio Vargas, 2006.

SACHS, I. Desenvolvimento includente, sustentável, sustentado. Rio de Janeiro: Garamond, 2004.

SANTOS, B. S. Pela mão de Alice. O social e o político na pós-modernidade. 7. ed. São Paulo: Edições Afrontamento, 1999.

SENNETT, R. Juntos: os rituais, os prazeres e a política da cooperação. Tra.: Clóvis Marques. Rio de Janeiro: Record, 2012.

SINGER, P. Falta representatividade a conselho. Folha de S. Paulo, 1999. Disponível em: <http://www1.folha.uol.com.br/fsp/brasil/fc14039912.htm>. Acesso em: 26 maio 2014.

SOUZA, M L. Desenvolvimento de comunidade e participação. 4. ed. São Paulo: Cortez, 1993.

VEIGA, C. E. L. Modelo de gestão da união e o roteiro de elaboração do PPA, para municípios. Brasília, Ministério do Planejamento, Orçamento e Investimentos Estratégicos, 2005.

VIEIRA, B. O. Serviço social: Processos e técnicas. 5. ed. Rio de Janeiro: Agir, 1981.

]Recebimento dos originais: 22/07/2014

Aceitação para publicação: 20/08/2014 